\title{
A Potential Hybrid Hole-Transport Material Incorporating a Redox Active Tetrathiafulvalene Derivative with CuSCN
}

Zheng-Zhen Tang, ${ }^{\dagger}$ Yi-Gang Weng, ${ }^{\dagger}$ Wen-Yu Yin, ${ }^{\dagger}, \star$ Miao Jiang, ${ }^{\dagger}$ Qin-Yu Zhu, ${ }^{* \dagger}$ and Jie Dai*†

†College of Chemistry, Chemical Engineering and Materials Science, Soochow University, Suzhou 215123, P. R. China

\#Key Laboratory of Advanced Functional Materials; School of Chemistry \& Materials Engineering, Changshu Institute of Technology, Changshu, 215500, P.R. China

\section{Characterizations and measurements}

\section{Figures}

Figure S1. The experimental powder XRD pattern and the simulated pattern from the crystal data of compounds $\mathbf{1}$ and $\mathbf{2}$.

Figure S2. IR spectra of compounds $\mathbf{1}$ and $\mathbf{2}$ as well as CuSCN.

Figure S3. Tauc plots for direct and indirect ban gaps of compounds $\mathbf{1}$ and $\mathbf{2}$ as well as $\mathrm{CuSCN}$.

Figure S4. Morphologies of the films pressed from powders of $\mathbf{2}$ (a) and $\mathbf{2}-\mathbf{I}_{\mathbf{2}}$ (b).

Figure S5. The experimental powder XRD pattern of $\mathbf{2}-\mathbf{I}_{\mathbf{2}}$ and the simulated pattern from the crystal data of compound 2.

Figure S6. IR spectra of compounds $\mathbf{2}$ and $\mathbf{2}-\mathbf{I}_{\mathbf{2}}$.

Figure S7. (a) Solid-state absorption spectra of $\mathbf{2}$ and $\mathbf{2}-\mathbf{I}_{\mathbf{2}}$. (b) Tauc plots of $\mathbf{2}$ and $2-\mathbf{I}_{2}$.

Figure S8. ESR spectrum of 2-I .

\section{Table}

Table S1. Crystal data and structural refinement parameters for $\mathbf{1}$ and $\mathbf{2 .}$

Table S2. The relative data to the calculation of the semiconductive properties for all the samples. 


\section{Characterizations and measurements}

General Remarks. Compound py-TTF-py was synthesized following the previously reported method. ${ }^{1}$ All analytically pure reagents were purchased commercially and used without further purification. Fourier transform infrared (FT-IR) spectra were recorded as $\mathrm{KBr}$ pellets on a Nicolet Magna 550 FT-IR spectrometer. Elemental analyses $(\mathrm{C}, \mathrm{H}$ and $\mathrm{N})$ were performed using a VARIDEL III elemental analyzer. Solid-state room-temperature optical diffuse reflectance spectra of the microcrystal samples were gained with a Shimadzu UV-2600 spectrophotometer using $\mathrm{BaSO}_{4}$ as a standard reference. Thermoanalytical measurements were performed using a TGA-DCS 6300 microanalyzer, and the sample was heated under a nitrogen stream of $100 \mathrm{~mL} \mathrm{~min}-1$ at a heating rate of $20^{\circ} \mathrm{C} \mathrm{min}^{-1}$. Powder X-ray diffraction (PXRD) data of the compounds were obtained using a D/MAX-3C X-ray diffraction meter with $\mathrm{CuK} \alpha(\lambda=1.5406 \AA)$ radiation. Cyclic voltammetry (CV) experiments were performed in solid state on a CHI650 electrochemistry workstation in a three-electrode system with a Pt plate working electrode, a saturated calomel electrode (SCE) as reference electrode, and Pt wire as the auxiliary electrode. X-ray photoelectron spectroscopic (XPS) measurements were recorded on a Shimadzu Axis ULTRA spectrometer.

X-ray Crystallographic Study. The crystal data were collected on a Bruker APEX-II CCD diffractometer for $\mathbf{1}$ at $120 \mathrm{~K}$ and a Rigaku Mercury CCD diffractometer for 2 at $223 \mathrm{~K}$ with graphite monochromated Mo $\mathrm{K} \alpha(\lambda=0.71073 \AA)$ radiation. An absorption correction (multiscan) was applied for all these compounds. The structures were solved by direct methods using SHELXS-16 program and the refinements were performed against $F^{2}$ using SHELXL-16. ${ }^{2}$ All the nonhydrogen atoms are refined anisotropically. The hydrogen atoms are positioned with idealized geometry and refined with fixed isotropic displacement parameters. Detailed crystal data and structural refinement parameters for $\mathbf{1}$ and $\mathbf{2}$ are listed in Table S1 in the Supporting Information. 
Theoretical Calculations. Density functional theory (DFT) calculations were performed using GAUSSIAN 09 program package for $\mathbf{1}$ and $\mathbf{2}$ at the B3LYP level. ${ }^{3}$ The basis set used for $\mathrm{C}, \mathrm{N}, \mathrm{O}, \mathrm{S}$, and $\mathrm{H}$ atoms was 6-31G, while effective core potentials with a LanL2DZ basis set were employed for $\mathrm{Cu}$ atom. ${ }^{4,5}$ The dinuclear packing units based on the crystal structures were used as the initial structures simplified model of the network of compounds $\mathbf{1}$ and $\mathbf{2}$ and further optimized to the minimum energy configurations.

\section{Device fabrication and measurements}

All the electrochemical measurements were performed on a CHI660E electrochemistry workstation in the ambient environment. The light source was a $150-\mathrm{W}$ high pressure xenon lamp without filter, which was positioned $20 \mathrm{~cm}$ from the devices.

(a) Device and J-V measurements.

A simple Schottky-type device was fabricated for all electrochemical measurements. The crystal samples were grinded into fine powder and a layer of the powder was paved an area of $0.500 \mathrm{~cm}^{2}$ on an ITO $(8 \Omega / \square)$ electrode with a mask. Another ITO electrode was covered on to be a sandwiched device and that was pressed by a clamp. The quantities of the samples were weighted as $1.5 \mathrm{mg}$ for all the compounds. The thickness of the sample layers were about $100 \mu \mathrm{m}$ measured by an electronic vernier caliper (Fowler). The $\mathrm{J}-\mathrm{V}$ plots were measured using the prepared devices in a two-electrode mode.

\section{(b) Mott-Schottky plot measurements.}

Mott-Schottky plots were obtained by impedance-frequency measurement with a three-electrode system. The working electrodes were prepared by a powder coating method. Weighed crystals of the compounds $(1.5 \mathrm{mg})$ were grinded and paved uniformly on an area of $0.500 \mathrm{~cm}^{2}$ ITO glass. A Pt plate and a saturated calomel electrode (SCE) were used as a counter electrode and a reference electrode. The supporting electrolyte solution was $0.1 \mathrm{~mol} \cdot \mathrm{L}^{-1}$ sodium sulfate aqueous solution. The 
capacitance of the semiconductor-electrolyte interface was collected at different frequency from 500 to $1000 \mathrm{~Hz}$.

(c) Calculation of the carrier density $(M)$ and the carrier mobility $(\mu)$.

In lower voltage range, a linear Ohm $\mathrm{J}-\mathrm{V}$ relation based on equation 1 is conducted:

$$
J=q N \mu_{0} \frac{V}{d} \quad(\text { Equation } 1)^{6}
$$

The carrier density $N$ can be evaluated according to the Mott-Schottky equation (equation 2) by a linear plot of $1 / C^{2}-V$.

$$
\frac{1}{C^{2}}=\frac{2}{q \varepsilon_{r} \varepsilon_{0} N A^{2}}\left(V-V_{F B}+\frac{K T}{q}\right) \quad(\text { Equation } 2)^{7} \quad(\text { Mott-Schottky) }
$$

In higher voltage range (the SCLC range), the carrier mobility $\mu_{0}$ is obtained based on equation 3 by a linear plot of $\mathcal{L}-V^{2}$.

$$
J=\frac{9}{8} \varepsilon_{r} \varepsilon_{0} \mu_{0} \frac{V^{2}}{d^{3}} \quad(\text { Equation } 3)^{6 \mathrm{~b}, 8}
$$

\section{References}

(1) Han, Y.-F.; Zhang, J.-S.; Lin, Y.-J.; Dai. J.; Jin, G.-X. J. Organomet. Chem. 2007, 692, 4545-4550.

(2) (a) Sheldrick, G. M. SHELXS-97, Program for structure solution; Universität of Göttingen, Göttingen, Germany, 1999. (b) Sheldrick, G. M. Crystal structure refinement with SHELXL. Acta Crystallogr., Sect. C: Struct. Chem. 2015, 71, 3-8.

(3) Frisch, M. J.; Trucks, G. W.; Schlegel, H. B.; Scuseria, G. E.; Robb, M. A.; Cheeseman, J. R.; Scalmani, G.; Barone, V.; Mennucci, B.; Petersson, G. A.; 
Nakatsuji, H.; Caricato, M.; Li, X.; Hratchian, H. P.; Izmaylov, A. F.; Bloino, J.; Zheng, G.; Sonnenberg, J. L.; Hada, M.; Ehara, M.; Toyota, K.; Fukuda, R.; Hasegawa, J.; Ishida, M.; Nakajima, T.; Honda, Y.; Kitao, O.; Nakai, H.; Vreven, T.; Montgomery, J. A.; Peralta, Jr., J. E.; Ogliaro, F.; Bearpark, M.; Heyd, J. J.; Brothers, E.; Kudin, K. N.; Staroverov, V. N.; Kobayashi, R.; Normand, J.; Raghavachari, K.; Rendell, A.; Burant, J. C.; Iyengar, S. S.; Tomasi, J.; Cossi, M.; Rega, N.; Millam, N. J.; Klene, M.; Knox, J. E.; Cross, J. B.; Bakken, V.; Adamo, C.; Jaramillo, J.; Gomperts, R.; Stratmann, R. E.; Yazyev, O.; Austin, A. J.; Cammi, R.; Pomelli, C.; Ochterski, J. W.; Martin, R. L.; Morokuma, K.; Zakrzewski, V. G.; Voth, G. A.; Salvador, P.; Dannenberg, J. J.; Dapprich, S.; Daniels, A. D.; Farkas, Ö.; Foresman, J. B.; Ortiz, J. V.; Cioslowski, J.; Fox, D. J. Gaussian 09, Revision A.1, Gaussian Inc., Wallingford, CT, 2009.

(4) Hay, P. J.; Wadt, W. R. Ab initio effective core potentials for molecular calculations. Potentials for the transition metal atoms Sc to Hg, J. Chem. Phys. 1985, $82,270-283$.

(5) Bharati, P.; Bharti, A.; Bharty, M. K.; Maiti, B.; Butcher, R. J.; Singh, N. K. Square planar $\mathrm{Ni}$ (II) complexes of pyridine-4-carbonyl-hydrazine carbodithioate, 1-phenyl-3-pyridin-2-yl-isothiourea and 4-(2-methoxyphenyl) piperazine-1-carbodithioate involving N-S bonding: An approach to DFT calculation and thermal studies, Polyhedron 2013, 63,156-166.

(6) (a) Li, X.; Hove, M. V.; Zhao, M.; Bakeroot, B.; You, S.; Groeseneken, G.; Decoutere, S. Investigation on carrier transport through AlN nucleation layer from differently doped Si(111) substrates. IEEE T. Electron Dev. 2018, 65, 1721-1727. (b) Zhang, W.; Simoen, E.; Zhao, M.; Zhang, J. Analysis of leakage mechanisms in AIN nucleation layers on p-Si and p-SOI substrates. IEEE T. Electron Dev. 2019, 66, 1849 -1855 .

(7) (a) Bera, B.; Chakraborty, A.; Kar, T.; Leuaa, P.; Neergat, M. Density of states, carrier concentration, and flat band potential derived from electrochemical impedance measurements of $\mathrm{n}$-doped carbon and their influence on electrocatalysis of oxygen 
reduction reaction. J. Phys. Chem. C 2017, 121, 20850-20856. (b) Liu, C.; Wu, W.; Liu, K.; Li, M.; Hu, G.; Xu, H. Orientation growth and electrical property of CuSCN films associated with the surface states. CrystEngComm 2012, 14, 6750-6754.

(8) Mihailetchi, V. D.; Duren, J. K. D.; Blom, P. W. M.; Hummelen, J. C.; Janssen, R. A. J.; Kroon, J. M.; Rispens, M. T.; Verhees, W. J. H.; Wienk, M. M. Electron transport in a methanofullerene. Adv. Funct. Mater. 2003, 13, 43-46. 


\section{Figures}
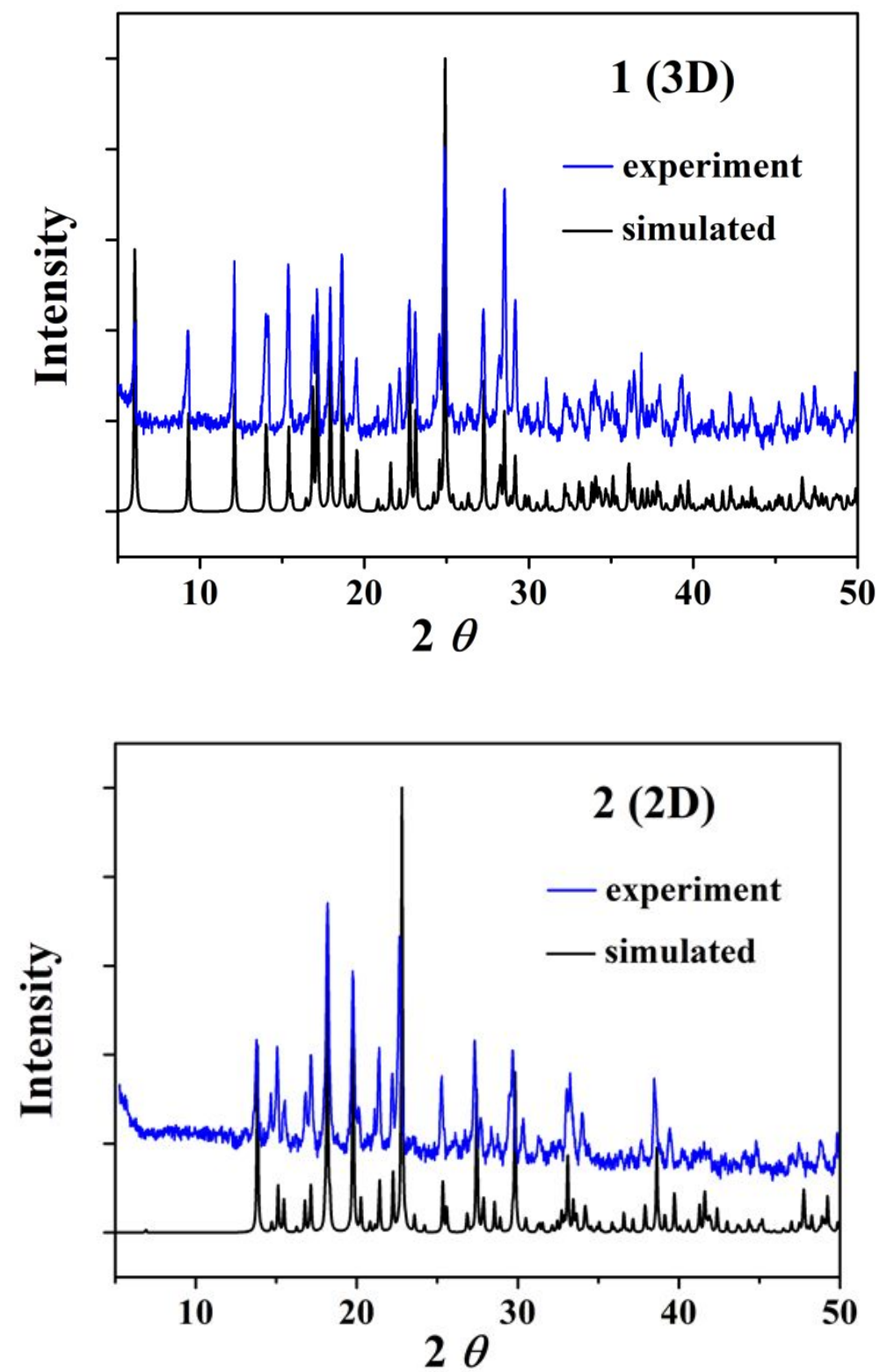

Figure S1. The experimental powder XRD pattern and the simulated pattern from the crystal data of compounds $\mathbf{1}$ and $\mathbf{2}$. 


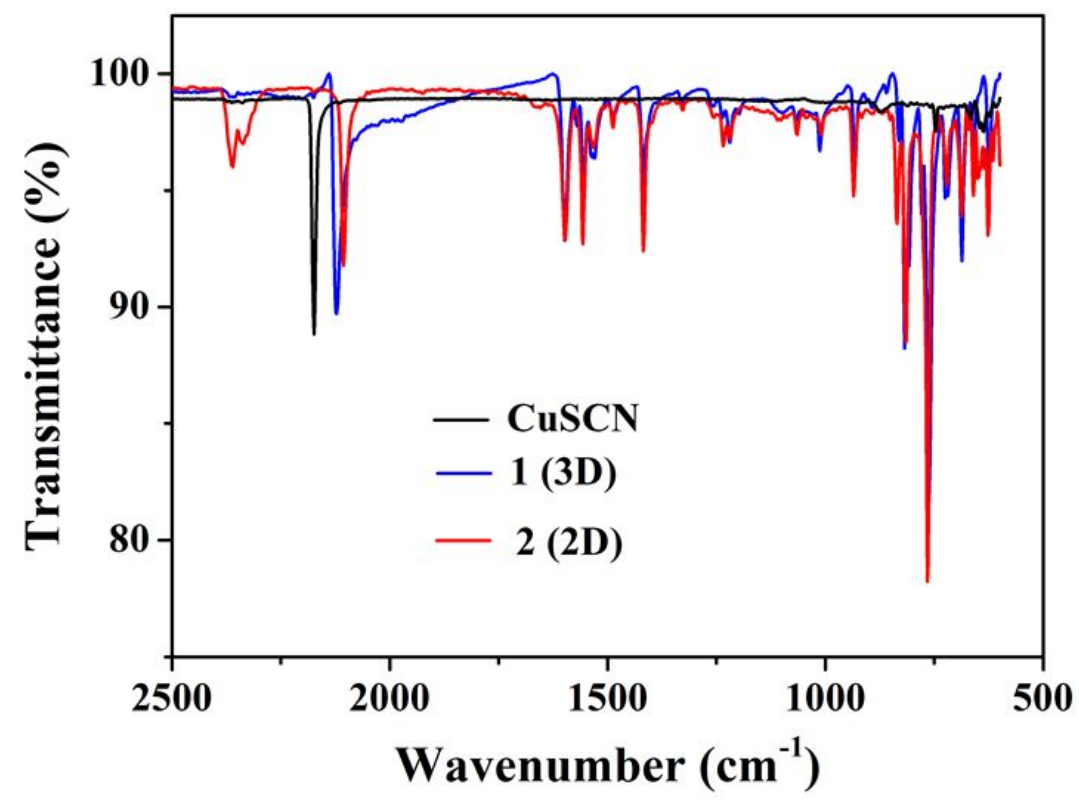

Figure S2. IR spectra of compounds $\mathbf{1}$ and $\mathbf{2}$ as well as CuSCN. 

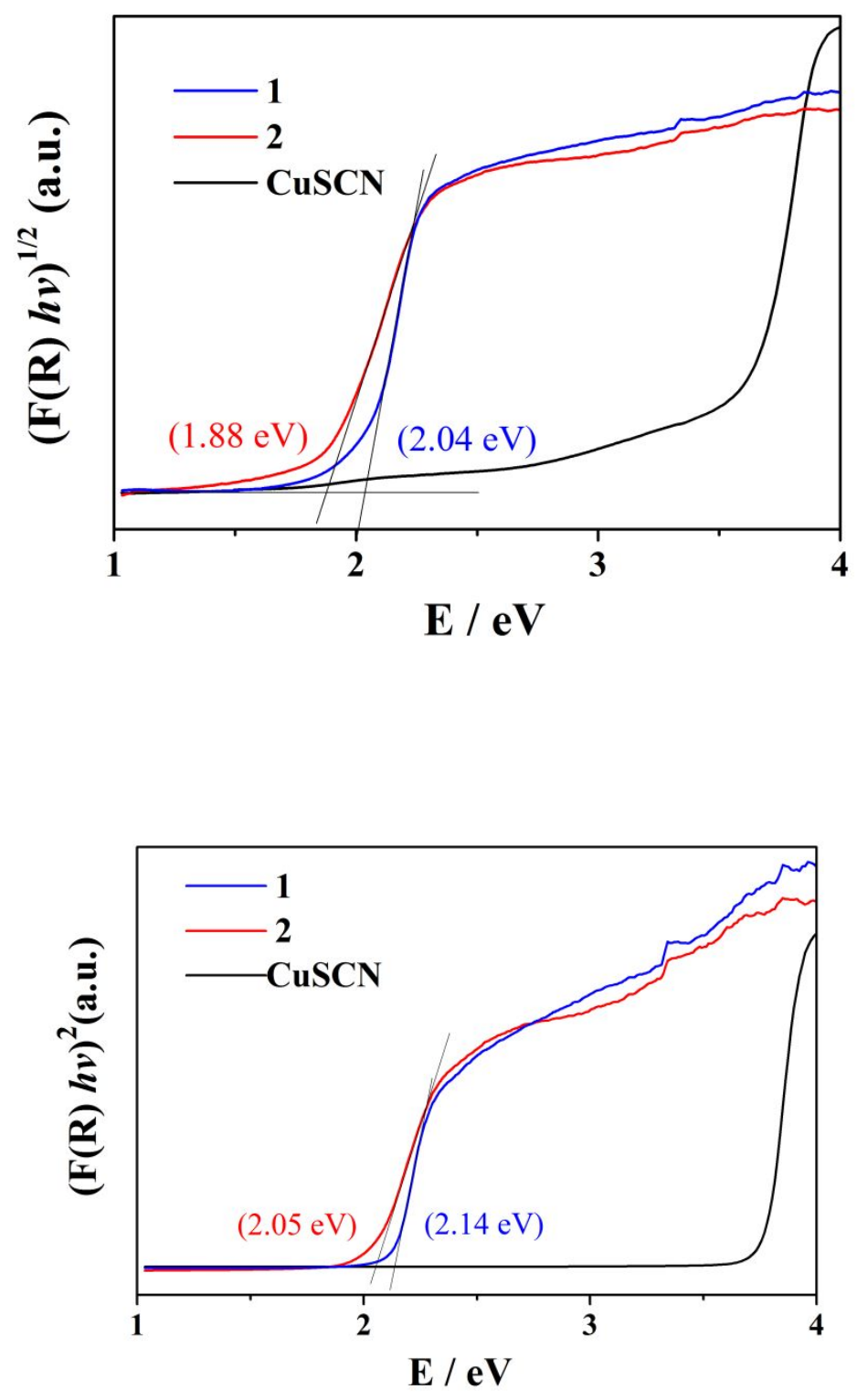

Figure S3. Tauc plots for direct and indirect ban gaps of compounds $\mathbf{1}$ and $\mathbf{2}$ as well as $\mathrm{CuSCN}$. 


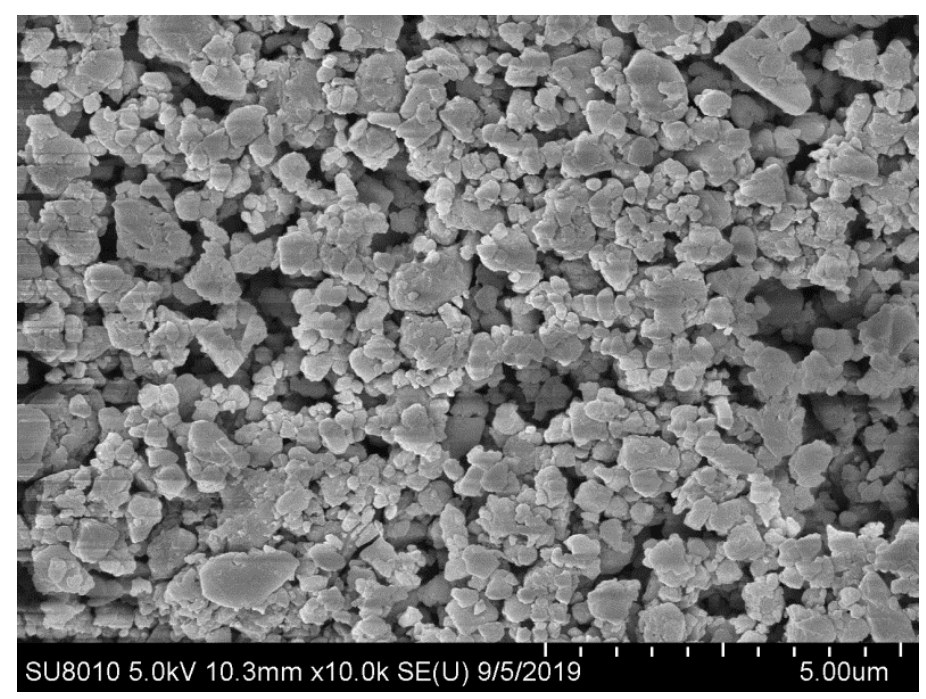

a

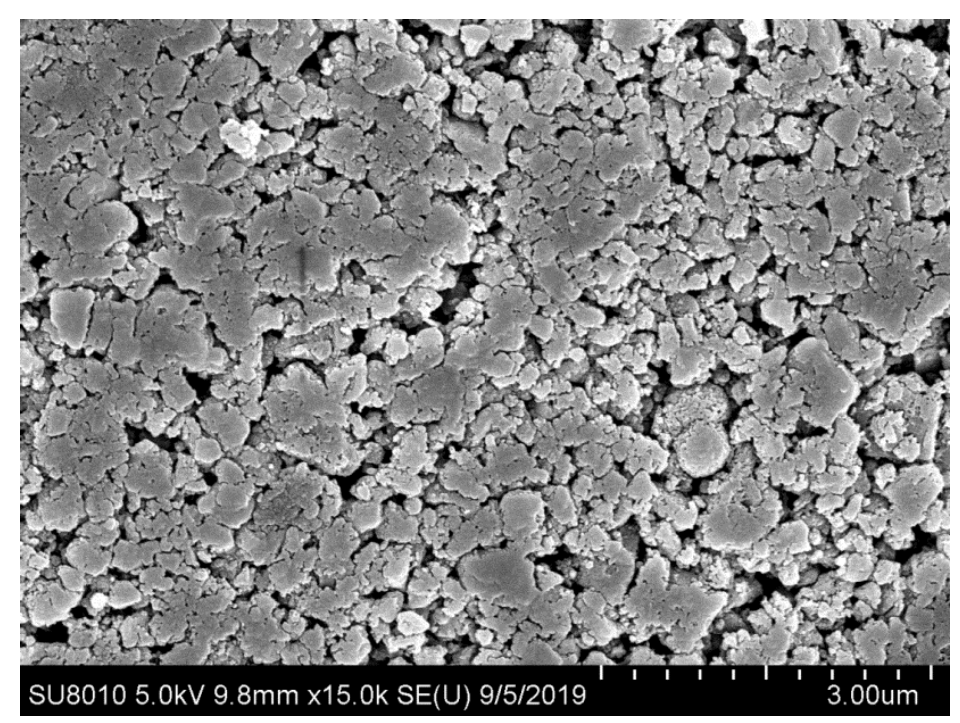

b

Figure S4. Morphologies of the films pressed from powders of 2 (a) and $2-I_{2}(b)$. 


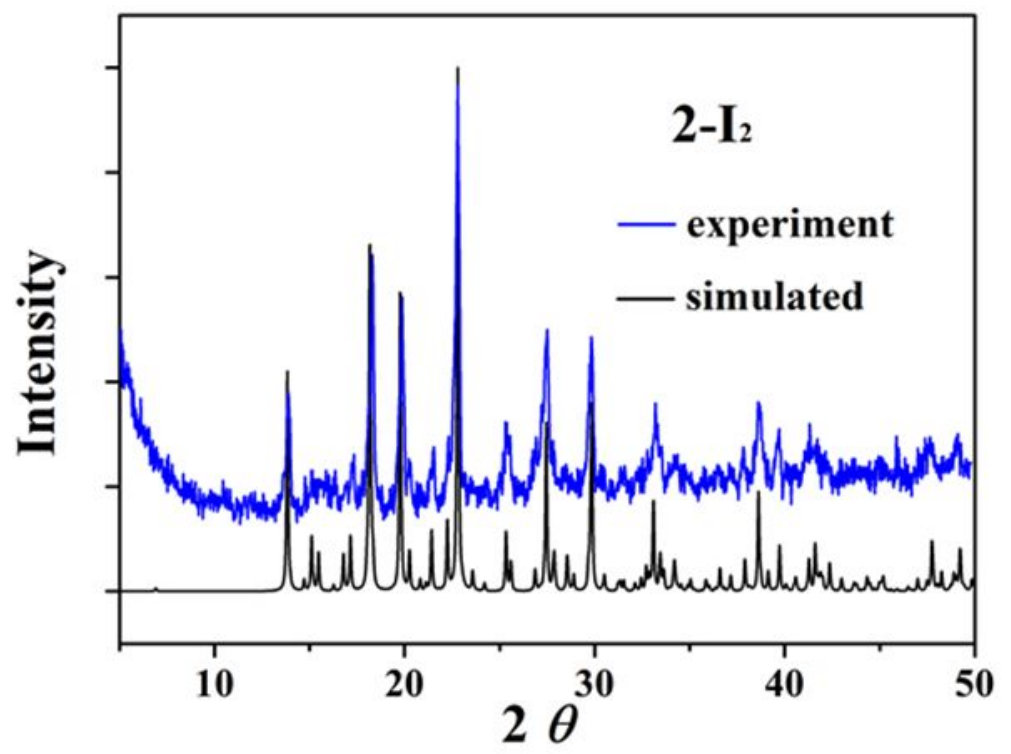

Figure S5. The experimental powder XRD pattern of $\mathbf{2}-\mathbf{I}_{\mathbf{2}}$ and the simulated pattern from the crystal data of compound 2.

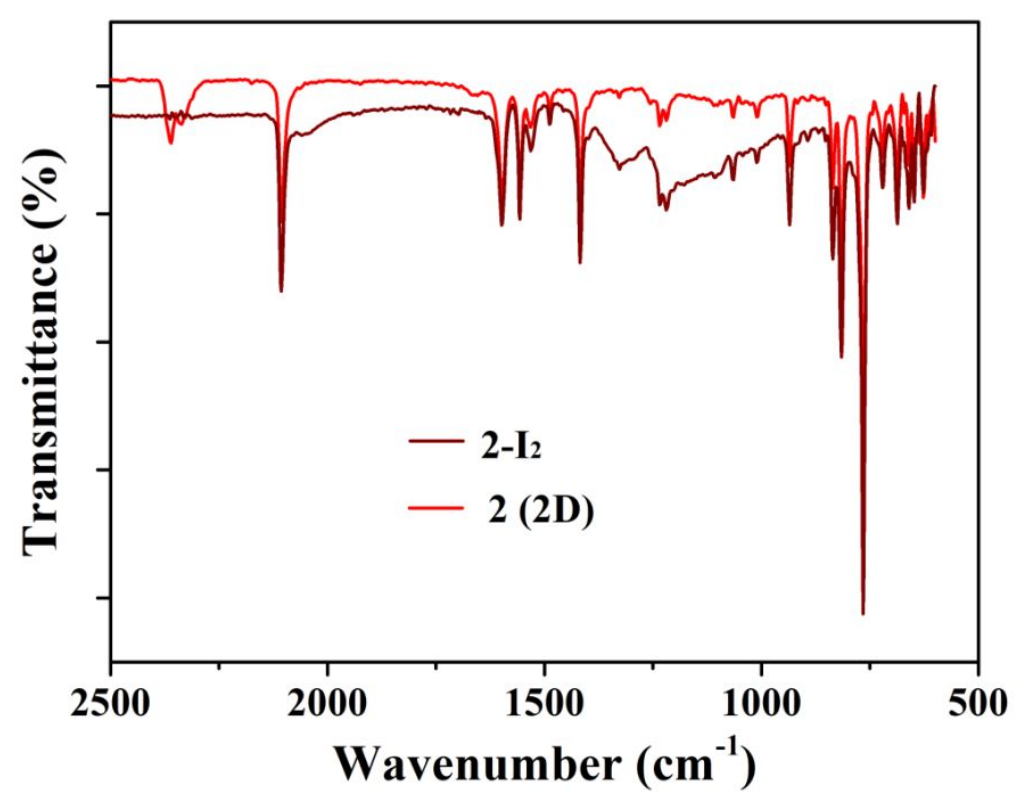

Figure S6. IR spectra of compound $\mathbf{2}$ and $\mathbf{2}-\mathbf{I}_{\mathbf{2}}$. 


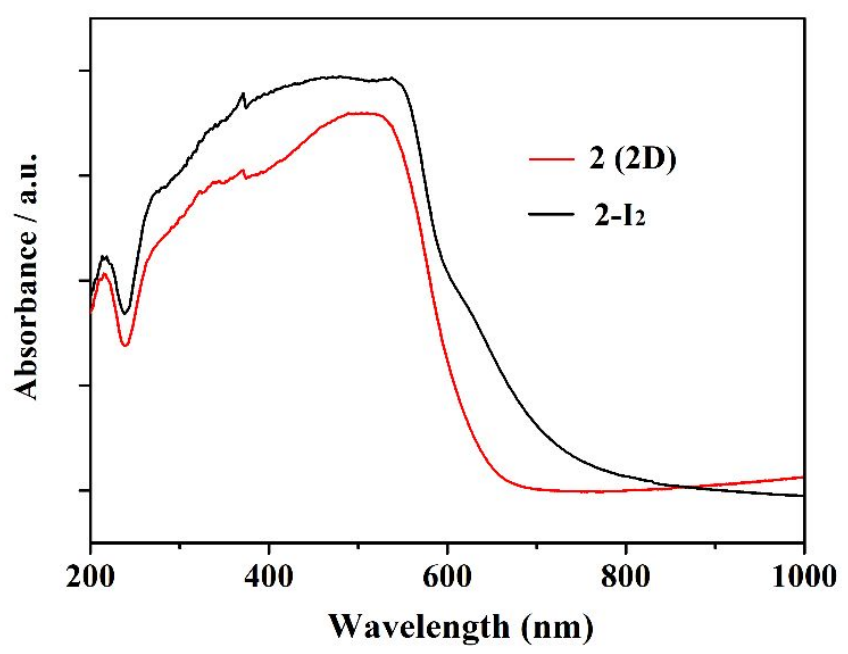

a

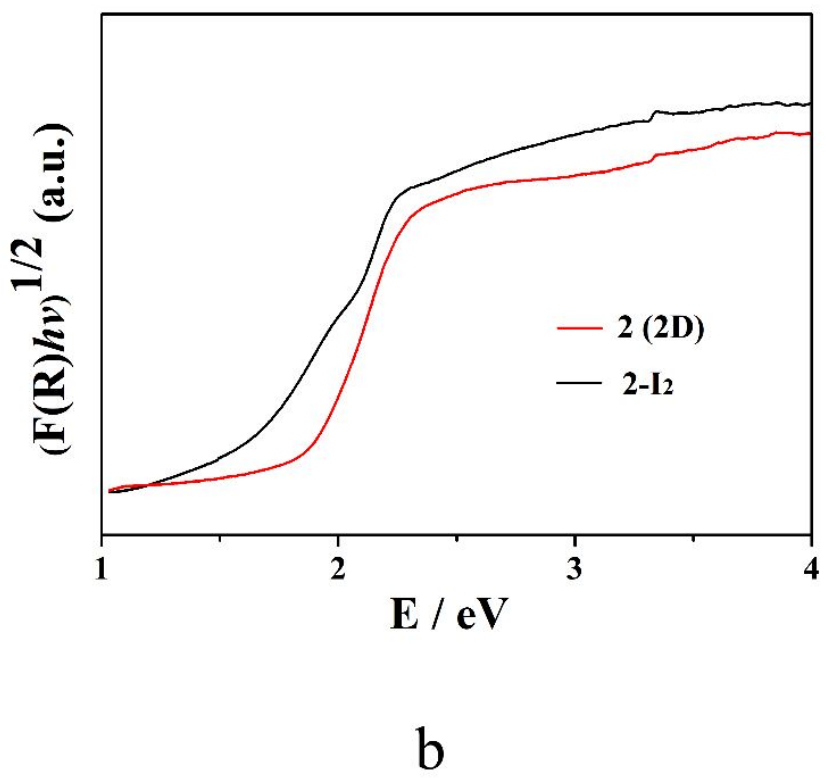

Figure S7. (a) Solid-state absorption spectra of 2 and 2-I 2 . (b) Tauc plots of 2 and 2-I 


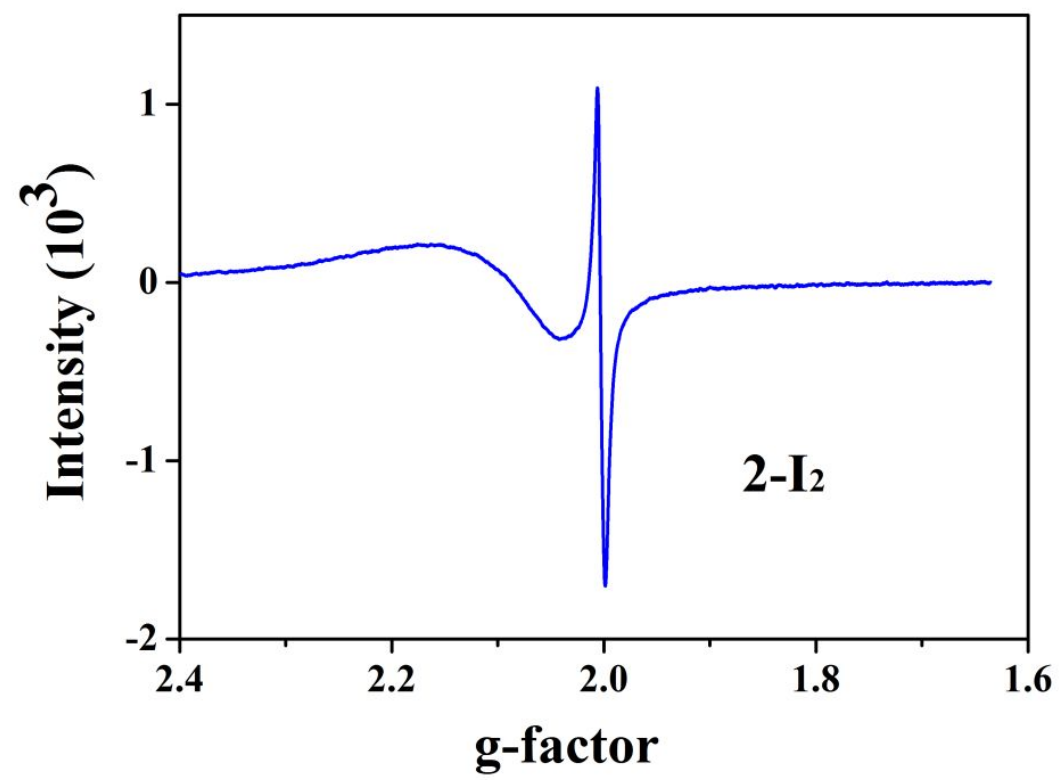

Figure S8. ESR spectrum of $\mathbf{2}-\mathbf{I}_{2}$. 
3. Table

Table S1. Crystal data and structural refinement parameters for $\mathbf{1}$ and $\mathbf{2}$.

\begin{tabular}{|c|c|c|}
\hline & 1 & 2 \\
\hline formula & $\mathrm{C}_{18} \mathrm{H}_{10} \mathrm{Cu}_{2} \mathrm{~N}_{4} \mathrm{~S}_{6}$ & $\mathrm{C}_{17} \mathrm{H}_{10} \mathrm{CuN}_{3} \mathrm{~S}_{5}$ \\
\hline fw & 601.74 & 480.12 \\
\hline cryst size $\left(\mathrm{mm}^{3}\right)$ & $0.10 \times 0.15 \times 0.30$ & $0.05 \times 0.15 \times 0.15$ \\
\hline cryst syst & orthorhombic & orthorhombic \\
\hline space group & Pna $_{1}$ & Pnma \\
\hline$a(\AA)$ & $29.221(6)$ & $12.031(4)$ \\
\hline$b(\AA)$ & $5.7865(12)$ & $25.580(7)$ \\
\hline$c(\AA)$ & $12.511(3)$ & $5.8718(18)$ \\
\hline$\alpha(\mathrm{deg})$ & 90.00 & 90.00 \\
\hline$\beta(\operatorname{deg})$ & 90.00 & 90.00 \\
\hline$\gamma(\operatorname{deg})$ & 90.00 & 90.00 \\
\hline$V\left(\AA^{3}\right)$ & $2115.5(8)$ & $1807.0(9)$ \\
\hline $\mathrm{Z}$ & 4 & 4 \\
\hline$\rho_{\text {calcd }}\left(\mathrm{g} \mathrm{cm}^{-3}\right)$ & 1.889 & 1.765 \\
\hline$F(000)$ & 1200 & 968 \\
\hline$\mu\left(\mathrm{mm}^{-1}\right)$ & 2.618 & 1.793 \\
\hline$T(\mathrm{~K})$ & $120(2)$ & $223(2)$ \\
\hline reflns collected & 39268 & 7918 \\
\hline unique reflns & 4799 & 2102 \\
\hline observed reflns & 3815 & 1738 \\
\hline no. params & 254 & 125 \\
\hline GOF on $F^{2}$ & 1.042 & 1.088 \\
\hline$R_{1}[\mathrm{I}>2 \sigma(I)]$ & 0.0536 & 0.0399 \\
\hline${ }_{W} R_{2} \quad[\mathrm{I}>2 \sigma(I)]$ & 0.1077 & 0.0762 \\
\hline
\end{tabular}


Table S2. The relative data to the calculation of the semiconductive properties for all the samples.

\begin{tabular}{lllllllll}
\hline & $\mathbf{C u S C N}(\mathbf{D})$ & $\mathbf{C u S C N}(\mathbf{L})$ & $\mathbf{1}(\mathbf{D})$ & $\mathbf{1}(\mathbf{L})$ & $\mathbf{2 ( D )}$ & $\mathbf{2 ( L )}$ & $\mathbf{2 - I 2 ( D )}$ & $\mathbf{2 - \mathbf { I } _ { 2 } ( \mathbf { L } )}$ \\
\hline $\mathrm{Cs}$ & $4.08 \times 10^{-5}$ & $4.05 \times 10^{-5}$ & $3.62 \times 10^{-5}$ & $3.71 \times 10^{-5}$ & $2.71 \times 10^{-5}$ & $3.16 \times 10^{-5}$ & $2.71 \times 10^{-5}$ & $2.76 \times 10^{-5}$ \\
$k_{1}$ & $1.85 \times 10^{9}$ & $1.82 \times 10^{9}$ & $2.24 \times 10^{9}$ & $2.69 \times 10^{9}$ & $2.24 \times 10^{9}$ & $2.23 \times 10^{9}$ & $2.95 \times 10^{9}$ & $2.25 \times 10^{9}$ \\
$k_{2}$ & $2.83 \times 10^{-4}$ & $5.61 \times 10^{-4}$ & $3.79 \times 10^{-8}$ & $1.94 \times 10^{-7}$ & $1.34 \times 10^{-7}$ & $8.09 \times 10^{-7}$ & $7.99 \times 10^{-4}$ & $2.45 \times 10^{-3}$ \\
\hline
\end{tabular}

(D) in dark and (L) in light.

Units: $\mathrm{C}, \mathrm{F} \mathrm{cm}^{-1} ; k, \mathrm{~F} \mathrm{~cm} \mathrm{~V}^{-1} \mathrm{~s}^{-1}$. 